\title{
Supervision Experiences of Rural School Counselors
}

\author{
Tara A. Wilson \\ Wayne State College \\ Susan Schaeffer \\ Chadron State College \\ Mary Alice Bruce \\ University of Wyoming
}

\begin{abstract}
This qualitative study explored the needs of professional school counselors and school counselor interns located in rural areas with regard to clinical supervision, consultation, and professional growth. Four separate focus groups ( $n=21)$ were conducted. To allow for consistency across focus groups, a series of six structured interview questions were used. Results of the data analysis revealed six themes which included unique issues of rural school counselors, dynamics of rural living, supervision from school administrators, supporting development through technology, desire for increased connection through supervision, and the identification of roles and responsibilities. Implications of this study indicate a crucial need to increase supervision training opportunities for current school counselors and interns. Technology and active participation with professional organizations may provide a platform for rural school counselors to receive supervision training and offer increased professional connection to solidify their counseling identity.
\end{abstract}

\section{Key Words: Rural, supervision, school counselors, roles and responsibilities}

While increased attention has been given to improving the clinical supervision of professional school counselors and school counseling interns (e.g., Lambie \& Sias, 2009; Luke \& Goodrich, 2012; Luke \& Gordon, 2012), little research has been conducted to determine what school counselors who are also site supervisors want and need to grow professionally. In particular, school counselors working in rural areas may present different perceptions for their advancement when compared to urban and suburban school counselors.

Rural school districts often present unique challenges for consideration (Oser, Biebel, Pullen, \& Harp, 2013; Rios, 1988). For example, weather and hazardous road conditions influence the ability to hold scheduled classes in rural school districts due to the reality of busing students from far-flung locations. Also, fewer student numbers often affect economic resources including budgets for employment and lessened access to opportunities for professional development that may result in educator burnout (Koch, 2007; Oser et al., 2013). Therefore, the purpose of this qualitative research study was to investigate the needs of rural professional school counselors and school counseling interns relative to clinical supervision, consultation, and professional growth.

\section{Supervision of School Counselors}

The importance of effective clinical supervision for all practicing counselors as well as those in training is a long established priority of the counseling profession (Bernard \& Goodyear, 2009; Council for Accreditation of Counseling and Related Educational Programs [CACREP], 2009). The focus on supervision needs is increased with the latest 2009 CACREP program standards for school counseling, which emphasize student learning outcomes based on competencies and demonstrated knowledge, especially as accomplished during hands-on experiences in the K-12 schools (CACREP, 2009). Comprehensive, developmental school counseling programs built on the guidelines of the American School Counselor Association National Model (ASCA, 2012) call for the counselors and interns to demonstrate skills and competencies related to advocacy, leadership, collaboration, and creation of systemic change. Following the American 
Counseling Association's Code of Ethics (ACA, 2014), consistent clinical supervision is needed to support the professional and personal growth of counselors and interns as they operate in complex work settings. The Ethical Standards for School Counselors (ASCA, 2010) also emphasize the need for effective supervision for both counselors (E.1.g.) and interns (F.3.) to ensure professional competence and best practices.

However, across work settings, school counselors seem to receive less supervision overall as compared to all other professional counselors (Somody, Henderson, Cook, \& Zambrano, 2008). While some counselors are involved in administrative supervision and consultation by which they may receive constructive feedback regarding the delivery of services aligned with the school's mission, they often receive less clinical supervision with focus on personal growth and improvement of counseling skills (ASCA, 2012; Luke, Ellis, \& Bernard, 2011). Recognition of the lack of clinical supervision expertise available for school counselors has brought forward several models meant to address the special demands of a school counselor's role in leading a school counseling program (e.g., Crutchfield \& Borders, 2006; Henderson \& Gysbers, 2006; Lambie $\&$ Sias, 2009; Luke \& Bernard, 2006). In addition, in a special section in the journal of Counselor Education and Supervision Miller and Dollarhide (2006) focused on the supervision of school counselors.

Miller and Dollarhide (2006) discussed two key issues that need to be addressed which include an increase of supervision training and noted appreciation for supervision of school counselors. Lacking adequate supervision training, a school counselor is not well prepared to mentor new school counselors into the profession effectively. Supervision facilitates the development of a solid professional identity and continued growth as a competent counselor. Without successful supervision and nurturing of new school counselors, delivery of effective services may decrease and result in the administrative assignment of noncounseling duties that take away from the entire school counseling program. In addition, often operating in isolation, lack of professional development opportunities with other colleagues who are site-based supervisors in rural areas may be even greater than for school counselors in metro areas due to potentially limited resources in the rural areas.

\section{Dynamics of Rural Living}

According to the U.S. Census Bureau (2010), rural as compared to metropolitan extends across more than $80 \%$ of the U.S. land mass and encompasses more than $17 \%$ of the U. S. population, almost 50 million people. Rural also encompasses the concept of frontier and is "all territory, population, and housing units in urbanized areas and in places of 2,500 or more persons outside urbanized areas" (US Census Bureau, 2010). While the definition of rural may be given quantitatively as compared to metropolitan, the nature of rural presents its own implications due to unique economic and social issues (Rios, 1988). Easy access to medical assistance, entertainment, shopping, and other resources often is limited due to geographic challenges. Travelling for specialized services takes time and money. Also, while the rapidly changing technology of today has enhanced social networking and communication, rural personal interactions may still revolve around family members, church alliances, and business colleagues. The school counselor also may serve in various roles in the community, such as the church usher and the basketball coach. With a small circle of social contacts and multiple roles, people know and observe each other's business and habits (Rios, 1988).

\section{Unique Issues for Rural School Counselors}

Realizing the implications of nonmetropolitan living, and acknowledging various attitudes that depend on the setting, school counselors face unique issues in rural and frontier areas (McCarthy, Van Horn Kerne, Calfa, Lambert, \& Guzman, 2010). Rural attitudes and behaviors widely vary depending upon economic stability and potential, population density, and increasing access to resources.

However, rural isolation often results in a tight sense of community, interdependence, and close family connections as well as a lack of trust for newcomers and outsiders (Saba, 1991).

Such isolation also may contribute to increased levels of stress and anxiety experienced by rural counselors who are busy attending to others and not taking care of themselves (Hendricks, Bradley, Brogan III, \& Brogan, 2009; Oser et al., 2013). School counselors may not have colleagues and other resources to provide support and consultation regarding self-care strategies, which can lower burnout symptoms (McCarthy et al., 2010). Balancing rural demands and available resources for counselors calls for positive professional relationships to provide needed support to focus on strategies for wellness (Oser et al., 2013). 
Other necessities for the rural school counselor include excellent interpersonal skills for collaborating with others. Counselors must network effectively and serve as the school liaison for other community resources and related agencies. In addition, counselors may serve as a mental health advocate and support others in understanding and prioritizing resources related to psychological issues (McCarthy et al., 2010).

Counselors frequently take on a generalist role due to a lack of specialists in small communities. Of necessity, counselors have to self-educate and consult across distances regarding specific issues they may encounter (McAdams III \& Wyatt, 2010). In a rural area, the counselor may be the only one possessing the trust of others and any qualifications germane to the situation.

Boundary issues also emerge as a significant worry for practicing school counselors in rural areas due to multiple roles and relationships with others (Hendricks et al., 2009). The counselor may have to put in a call to report abuse for a family whose parent is the local banker and the other parent is a school board member. Since people often turn to those whom they trust, specific safeguards, knowledge of ethical codes, and a high level of communication are essential to maintaining clear expectations and monitoring accessibility (Erickson, 2001).

Understanding the local culture, laws, and expectations are essential to continuing respect and credibility as a competent professional. A counselor realizes the general values of the community and how they may intersect with the counselor's values and behaviors (Hann-Morrison, 2011; Sutton \& Pearson, 2002). A counselor may choose to avoid public alcohol use, use care in dating, and feel pressure to engage in local gatherings such as the farmer's market and religious celebrations.

Issues of diversity, such as ethnicity and sexual orientation, stand out in rural communities. Counselors must be sensitive to the needs and prejudices that may exist in a small community that holds traditional values. As an advocate with high visibility, the counselor often must take a stance and speak out to reduce prejudices. A counselor seeks to increase cultural competencies and responsiveness for all students including those exploring various affectional relationships, coming from assorted SES levels, and needing special services (Luke \& Goodrich, 2012).

Meanwhile, electronic communication and social networking offer numerous opportunities for possible connections related to supervision, consultation, and professional development (McAdams III \& Wyatt, 2010). Webinars and podcasts offer a wealth of information easily obtainable by school counselors. Audiovisual media, e-mail communication, and other rapidly changing technology-assisted practices can support the professional needs of school counselors and interns (Luke \& Gordon, 2012).

In summary, when considering the need to enhance the supervision of the rural school counselor, one needs to be aware of the cultural differences, limitations, and resources of rural communities in order to provide access to supervision. Rural school counselors are aware of the need of supervision, and that the resources for supervision may come through distance and technology assistance.

\section{Method}

Counselor educators who have taught and worked with counselors in rural areas conducted this qualitative study. A qualitative method allowed for participants to share their unique stories and perspectives (Merriam, 2009) as they relate to the rural or frontier work environment. Further, a grounded theory approach (Corbin \& Strauss, 2008) was used to understand the school counselors' supervision process. The study was approved by the university review board.

\section{Participant Selection}

A total of 21 school counselors from frontier and rural areas located throughout the western United States were invited to participate in the study. Participants were purposefully selected to fit the parameters of this study (Patton, 2002). The researchers extended lunch invitations to the select school counselors who were practicing in small towns within three western states. The invitations included the informed consent and described the study as related to school counseling and supervision. As the researchers were counselor educators, several of the school counselors were also interns completing their counseling program. All invitees accepted the invitation and expressed interest in sharing their experience. One respondent stated, before the actual meeting, that he was excited to share his experience and have someone listen. Several participants expressed that seldom had anyone seemed interested in the rural school counselor experience.

\section{Participant Demographics}

Eighteen of the participants were female and three of the participants were male. The number of 
students within the districts in which the school counselors worked ranged from 56 students to 2,500. Two participants were employed at schools within a Native American reservation. Two of the participants did not have experience as a teacher. This may have been related to the department of education's mandate in one of the included states that school counselors have a teaching certificate and two years' experience as a teacher. Seven of the twenty-one participants completed their degrees and were practicing as school counselors. Five of the remaining fourteen were also practicing as school counselors while completing an internship in their Master's program. The remaining nine participants were completing their internship for their master's degree in school counseling as well as teaching within their school systems. All of the districts in which the participants were involved had counseling K- 12 positions. Six of the participants were working as a K-12 counselor. In total, participants were gathered from three western states and were working across multiple school districts.

\section{Data Collection and Analysis}

The researchers conducted four separate focus groups in different locations to accommodate distance among participants. A meal was provided by the researchers for all of the participants. Each focus group lasted between one and a half to two hours. A constructivist perspective underlined the data collection as participants socially constructed their answers in group interactions (Merriam, 2009). Ten questions were prepared to encourage stories to be shared. However, in the process of interviewing the participants, to meet time constraints only six of the ten questions were used. The questions posed to all participants included:

1. Describe the rural supervision process.

2. What are the supervision special needs for rural school counselors?

3. What would it look like if you had the supervision you desired to grow with?

4. What opportunities are available for professional development in rural settings?

5. What is most helpful from supervision? What is most helpful for rural school counselors?

6. What would you like to share about the rural school counselor experience?

These questions facilitated the conversation in each of the four focus groups. Connections were made among the participants when answering these questions that encouraged the sharing of their individual experiences. During the meeting, detailed notes were taken by each researcher. The data were analyzed to identify themes that gathered a deeper and more defined understanding of the rural school counselor experience. Specifically, each researcher coded all data separately and then discussed codes in depth to reach an agreement on more general themes that were representative of data collected across focus groups. Analysis included both open coding and axial coding (Corbin \& Strauss, 2008). Open coding entailed examining the properties and dimensions of the data, while axial coding consisted of finding relationships between concepts. Initially, open coding revealed a multitude of themes, which were then narrowed down, through axial coding, to six overarching themes.

Triangulation was used to enhance the credibility and consistency in this research study (Merriam, 2002). Specifically, triangulation in the form of using multiple investigators and gathering data from multiple focus groups aided in this study's credibility. Each focus group had at least one researcher present, while one focus group had two researchers present. Further, participants were purposely recruited from different geographical areas to allow for a variety of perspectives. Additionally, after the data were analyzed, and themes were identified, a member check was conducted. The researchers shared the themes with participants, requested feedback, and made minor edits to ensure the themes were an accurate representation of participant experiences.

\section{Results}

Six major themes emerged based on the experience of the participants. Four themes were found in previous literature including unique issues of rural school counselors, dynamics of rural living, supervision from school administrators, and supporting development through technology. Additionally, two themes emerged that were not previously found in relevant literature and included a desire for increased connection through supervision as well as the identification of roles and responsibilities. Throughout the group discussions, the interns joined in agreement with the school counselors and expressed examples mirroring those of the counselors. Each major theme is discussed in further detail.

\section{Unique issues of Rural School Counselors}

The majority of participants in the focus groups expressed ideas related to unique issues of rural school counselors. A school counselor in a small school stated, "In a larger school, tasks are divided, but in a small school, I am it. I am the one. And, I 
am headed to burnout." I think a supervisor would call me on that. Another school counselor in a smaller school shared her experience with isolation, observing "I wear many hats and have little time, since I am alone," a statement which received head nods from other participants in the focus group. Participants across focus groups joined in a discussion related to being the only school counselor as well as the only mental health professional in a very small town.

The participating school counselors also commented on the high visibility of the rural environment in that community members are comfortable with the school counselors and felt free to contact them about any worry related to their children or family. Another participant further added her experience with boundaries and shared, "I do it all alone. I know that boundaries are loose. Sometimes I don't realize it is happening to me when emotions are high." While encouraged that people are becoming more at ease with counseling services, participants identified the need for a supervisor who would support them in finding ways to say "no" to protect their personal and professional health.

Participants also shared experiences around a common issue in rural communities, that of being a part-time classroom teacher as well as the school counselor in the building. "Talk about stress, sometimes an emergency occurs, and I need to continue in my classroom while handling a worrisome situation." Building on the idea of anxiety and stress, participants described feeling overwhelmed and needing a counseling supervisor for emotional support that may not be easily available due to confidentiality concerns. Often for these participants, the building administrator served as the supervisor, sometimes resulting in little emotional understanding and thus adding to ethical dilemmas and lack of clear direction. While a counselor is a student advocate, an administrator usually prioritizes a very different agenda when considering problemsolving and decision-making processes in a school system. Meanwhile, a broad spectrum of responsibilities, including parental legal rights, confidential relationships with students, teachers' input, and feedback from support staff including custodians, bus drivers and cooks were mentioned as sometimes overwhelming for a rural school counselor.

\section{Dynamics of Rural living}

Many dynamics of rural living were discussed that formed barriers to the school counselor's work and prohibited the participating school counselors from receiving the supervision they desired to receive. The most commonly discussed barriers included high responsibility, high visibility, and lack of resources. With regard to the high responsibility associated with the job, an experienced school counselor shared that she was expected to "know everything and do everything," forcing the school counselor to take more of a generalist approach. Such 24/7 responsibilities seemed to contribute to a school counselor's workload, leaving little free time to seek clinician supervision. Another school counselor expanded on his busy workload and shared that he was only assigned to the high school; however, no counselor was assigned to the elementary school. Therefore, when necessary he was called to the elementary school to handle emergency situations. This high level of responsibility not only added stress to school counselors' workloads, but also illustrates the lack of resources often found in the isolated, rural environment.

Another school counselor questioned from whom she would be able to seek supervision from due to the high visibility and inter-connection of everyone knowing everyone in rural environments. Such high visibility frequently leads to professional isolation due to the confidential nature of the work of a school counselor. Some participants further shared that they did not have anyone to go to for supervision or even to discuss the stress that is associated with their jobs.

\section{Supervision from School Administrators}

The participants acknowledged a need for clinical supervision; however, most participants also noted that the majority of the supervision they receive is from their administrators. While clinical supervision focuses on conceptualization, personalization, and skills (Bernard, 1979), administrative supervision involves fulfillment of the expectations and the responsibilities of the school counselor's job duties. One participant expressed frustration with administrative supervision and stated, "Administrators understand what we do and can't do, but they still lump us in with the teachers." Another expressed the variety of expectations placed upon them from different administrators and shared, "Different administrators have different guidelines. Some want you there all the time and some want you to go [to trainings]. It depends on the individual personality of your supervisor, and what they deem is valuable." Another participant expressed the value using data collection to prove the effectiveness of 
their program to the administration, while also validating the need to attend certain professional development opportunities to supplement knowledge.

Additionally, some participants discussed the difference between supervision they received while in graduate school, studying to become a school counselor, and the supervision they currently received as an employed school counselor. One school counselor suggested that peer-to-peer supervision could be valuable; however, a program was not in place for such supervision. Others shared that they participated in more consultation than supervision because they "just don't have the time... [although it] would be good for us to have the kind of supervision we had in the program." Other barriers that may contribute to a lack of supervision in rural schools include isolation as the only school counselor in the school, lack of funding to pay for supervision services from a qualified professional, or not having any additional time in their workday to receive supervision.

\section{Supporting Development through Technology}

Due to the isolated nature of the rural environment, many participants shared the benefit of using technology to increase connections among school counselors. Current uses of technology that helped increase connection included being on group email list servers, using an encrypted internet connection to communicate via video conference, and accessing the American School Counseling Association website for resources. One participant emphasized the need for connections to be made not only among school counselors but also with other professionals, as well. She shared, "since we all have mental health responsibilities, it would be great to have access to lots of resources to help me know how to deal with specific issues."

Given the isolated nature of rural environments with a scarcity of resources, taking an interdisciplinary approach offers many advantages. An interdisciplinary approach may make the most of the resources in the area and offer a holistic approach to student care. Toward the end of one focus group, an inspired counselor stated, "We need to get going with technology It is used in the classroom and talking about this now together has me thinking I could get some supervision online." Although technology can be used to support connections among school counselors, it may not always be easy to access. For example, in order to receive online supervision, the Internet connection would need to be encrypted to ensure the confidentiality of shared information.

\section{Desire for Increased Connection and Supervision}

Despite busy schedules, and perhaps due to the stress of the school counselors' jobs, many participants expressed a desire for increased connection. "I wish we would all meet every month across [the state] like we used to do on compressed video," was one aspiration shared by an experienced counselor. Another counselor in response to another participant's experiences, noted they were happy that they resided in a town large enough to meet with multiple school counselors on a monthly basis.

However, in more isolated areas, and as was the case with some of the participating school counselors, there may be only one school in the area with one school counselor assigned to the kindergarten through senior grade levels.

\section{Identifying Roles and Responsibilities}

While most participants seemed to have a clear understanding of a professional school counselor's duties when leading a school counseling program, they expressed worries about the role confusion and others' mistaken expectations. One participant described the helpful supervision experienced during internship that resulted "in meaningful collaborations and discussion to identify counselor roles. If I were unsure, I just checked in with my supervisor." Another experienced school counselor told of "needed clarity regarding connections with mental health agencies and drug court officials. I would appreciate ongoing feedback as to the appropriateness of my role in the community and how I can best serve in that role." The discussion further expanded the idea of properly working with mental health resources and one individual commented,

\footnotetext{
A supervisor could support us in learning how to connect with those in the community as well as let them know our capabilities and duties. We need the feedback of a clinical supervisor to network effectively in a highly professional manner, especially when managing conflicts and power struggles.
}

Meanwhile, a number of participants in various focus groups expressed concern about how different administrators and other educators hold discrepant expectations for school counselors. According to one school counselor, "We need a solid identity and consistent message concerning our role which I think clinical supervision could clarify with encouragement and insightful reference to the ASCA standards." 
There was a shared understanding that school counselors are focused on the health and wellness of all students, pre-kindergarten through high school seniors, with a focus on academics, career and social/emotional domains. Given the multiple roles, many participants offered examples of additional, and at times, unrealistic expectations for counselors. One participant pointed out the demand by special educators for help with students with special needs in a multitude of tasks such as "documented behavior plans, strategic planning related to resources and financing, and required meetings." Another member added, "With the Response to Intervention (RTI) federal and state requirements, the special educators and administrators are expecting our leadership with that too. I don't have time."

Other participants expressed frustration with administrators adding other special projects to their list, such as concerns involving transit families, absences, and dropouts. The consensus appeared to be in-keeping with one individual's conclusion, "With real clinical supervision, I could confidently put forward a job description plus address what is pushing my buttons with all these roles and responsibilities and what part I play in the excessive expectations that arise."

\section{Discussion}

The findings of this study provide awareness to the supervision needs of school counselors practicing in rural locations and identify possible strategies for needed support. Rural school counselors are faced with unique issues which may include isolation, boundary issues, and little emotional understanding from administrative supervisors. As previous research indicates, school counselors receive less supervision to aid in such issues as compared with other professional counselors (Somody et al., 2008). However, rural school counselors may benefit from clinical supervision to help navigate issues as they arise. For example, when compared with an administrative supervisor, a clinical supervisor might provide more empathetic understanding to the stress of a school counselor.

Many dynamics of rural living systemically impact the work of a school counselor. For example, the high level of responsibility of rural school counselors, coupled with a lack of resources in the more isolated communities, causes many school counselors to take a generalist approach. Further, school counselors are highly visible in their communities and are often approached by parents and students during outings in the community. Therefore, establishing clear boundaries through clinical supervision may be helpful.

However, the dynamics of rural living may also be potential strengths for rural school counselors. School counselors, for instance, are not the only professionals that are highly visible in the community. Medical doctors, lawyers, and other professionals are highly visible in the isolated communities. Due to the close nature of rural communities, rural school counselors may be able to establish relationships with multiple professionals allowing them to work together in collaboration.

School counselors are typically supervised directly by school administrators. While administrative supervision is necessary, this is not equivalent to clinical supervision. While administrative supervision might consist of job performance and evaluation, clinical supervision takes a deeper look at conceptualization, personalization, and skills (Bernard, 1979). Unfortunately, there are barriers to receiving clinical supervision in rural school settings. Two of the most common barriers reported by participants in the current study included a busy day that left little time for clinical supervision and not being able to identify a potential supervisor in the rural community.

One aspect addressed in clinical supervision, which may not be emphasized in administrative supervision, is the wellness of the counselor (Storlie \& Smith, 2012). Maintaining emotional wellness though self-care strategies continues to be an important task of counselors and may decrease the risk of job burnout. Many school counselors in rural settings are the only individuals in the counseling department and face isolation. While there are many professionals in the school, non-school counselors may not understand the responsibilities of the counseling position that include balancing testing, scheduling, crisis counseling, and maintaining confidentiality with many other duties (Bardhoshi \& Duncan, 2009). Therefore, school counseling interns may benefit from discussing the self-care strategies of the counselor in addition to the necessary case management supervision.

Clinical supervision may also be able to provide a better understanding of the school counselors' responsibilities and available resources in the isolated communities. Therefore, it may be beneficial to take an interdisciplinary approach to supervision or consultation. For example, consultation with mental health community counselors may help the school counselor make referrals when necessary. 
Supervision also brings forward the intern as a colleague who can team with the counselor to regroup and re-emphasize counseling as opposed to noncounseling duties. During our study, the counselors expressed appreciation for the renewed perspective and creative ideas brought by their interns.

Additionally, the more isolated, rural areas that the participating school counselors serve may benefit from a centralized regional meeting. In one focus group, a member regretfully shared that at one time counselors gathered for an organized regional meeting, but it had since dwindled. The busy schedules, paired with the miles that would have to be traveled to meet in a centralized location, may have impacted the success of the group meeting. Further, during some winter months, weather conditions may prohibit members from attending a centralized meeting. These factors need to be taken into consideration before organizing centralized meetings where counselors could receive supervision. However, as many participating school counselors offered, a strategy to increase connection among school counselors may be through the use of emerging technologies.

Given the isolated nature of rural environments, technology may be useful for providing clinical supervision to numerous rural school counselors. For example, email and videoconferencing may help connect supervisors and supervisees in between the traditional face to face interaction (Luke \& Gordon, 2011; Luke \& Gordon, 2012). Additionally, rural school counselors benefit from taking advantage of web-based supervision training modules (Swank \& Tyson, 2012). Due to the isolated nature of rural communities, technology can help bridge the gap between scarce resources.

Making use of technological advances in clinical supervision can assist school counselors increase connectivity with others through peer-to-peer supervision or consultation. For example, technology in the form of videoconferencing or organization of a centralized meeting might be useful to help establish connections in the isolated rural environments. However, face-to-face interactions with other school personnel may also be beneficial. A clearer comprehension of the roles and responsibilities of the school counselor could increase connections and empathetic understanding.

The final theme found in the literature and in the current study dealt with identifying roles and responsibilities. At times, school administrators and other key stakeholders may not fully realize the profession of the school counselor (Bardhoshi \& Duncan 2009). For example, it may be necessary to discuss the policy of confidentiality with school administrators (O'Connell, 2012). Identification of ethical limitations as well as school policies is necessary to fully support students. Therefore, communication and collaboration among key school professionals is essential. One potential strategy for informing others on the roles and responsibilities of the school counselor includes a daily or weekly schedule placed in a visible location. Not only does this schedule show the activities of the school counselor, it also helps students and staff locate the school counselor during times of an emergency.

\section{Implications}

The results of this study indicate a need to increase training opportunities in supervision available to rural school counselors. While knowledge and skills are shared via conferences and workshops, there is a need for a focus to be on supervision training. Furthermore, rural school counselors have a professional responsibility to take advantage of opportunities for supervision training as the topic may only be briefly covered in initial academic training.

Technology also provides a platform for peer supervision among counselors who are separated by miles of travel. Rapidly changing technology can increase the personal connection among typically isolated rural school counselors. Supervision through the use of technology needs to be over a secure internet connection to ensure information remains confidential. Further, a mentorship between a more experienced rural school counselor and a novice school counselor may be an additional way to support an enjoyable and meaningful relationship with another professional school counselor (Bickmore \& Curry, 2013). State, regional, and national school conferences offer opportunities to form potential mentorship connections with others, while technology could facilitate the continuance of the mentoring relationships.

Another avenue that may assist rural school counselors is active participation within professional associations. This needs to come from both directions, from members and the leadership of the associations. Combined with the access of technology, this is a use of current resources and provides the one-to-one contact that many of the rural school counselors desire. Encouragement from the 
local district to take part in the professional development will assist, as well.

Interning school counselors may benefit from additional training while still enrolled in a training program. Clinical supervisors for interning school counselors can alert and prepare school counselors to the unique challenges of working in a rural setting. Encouragement to find an experienced mentor and to stay active in professional organizations strengthens the future school counselor's potential for success. Additionally, discussing roles and responsibilities of school counselors during the internship class of the future school counselor can be helpful to integrate knowledge into practice.

During our study, interns expressed admiration for the practical application and insights described by the school counselors. In like manner, the school counselors referred to the renewed energy, hope, and collegiality brought by the interns. Bringing together the two groups appeared to reinforce counselor identity and elevate the expression of appreciation for one another during each focus group.

\section{Future Research}

A clear need exists for additional future research regarding the supervision practices of rural school counselors. For instance, as school counselors gain experience in rural settings, do they form deeper connections? This question came out of a discussion counselors had as they were discussing their own longevity and networking within their positions, and how they were recruited into the counselor role. The professional identity of the school counselor also needs to be addressed in future research, specifically, the many roles of the rural school counselor including the identity as an educator and as a counselor. Additionally, it may be beneficial to address the expectations of clinical supervision of school counselors and what could enhance their supervision experiences. Another consideration that the study brought out is how counselor development may play in some of the responses. Several of the participants were completing their internship, while the majority of the participants were experienced in the positions. Whether intern or counselor, all were clear that professional school counselor identity needs to be solidified as well as counseling and noncounseling duties. Throughout a counselor's career whether as a beginning student intern or experienced counselor, professional development was recognized as crucial for rural school counselors.

\section{Conclusion}

Rural communities possess characteristics that can be assets to rural school counselors. The tightknit communities offer opportunities to increase connection among professionals and, therefore, provide a more holistic approach to support students. However, along with the strengths, there are also characteristics that make school counseling in rural environments stressful. The rural school counselors and interns in this study acknowledged a need for clinical supervision. There are many benefits of clinical supervision including, building a solid professional identity, improved school programs, and students who are healthier (Dollarhide \& Miller, 2006). Therefore, increased supervision through the use of centralized meetings, peer-to-peer supervision, and the use of technology may be one way to overcome these challenges.

\section{References}

American School Counselor Association. (2010). Ethical standards for school counselors. Retrieved from http://www.schoolcounselor.org/asca/media/asca /Resource\%20Center/Legal\%20and\%20Ethical \%20Issues/Sample\%20Documents/EthicalStanda rds2010.pdf
American School Counselor Association. (2012). The ASCA national model: A framework for school counseling programs (3rd ed.). Alexandria, VA: Author.

American Counseling Association. (2014). ACA code of ethics. Retrieved from

http://www.counseling.org/docs/ethics/2014-acacode-of-ethics.pdf?sfvrsn $=4$

Bardhoshi, G. \& Duncan K. (2009) Rural school principal's perceptions of the school counselor's role. The Rural Educator, 30(3), 16-24. 
Bernard, J.M. (1979). Supervisor training: A discrimination model. Counselor Education and Supervision, 19, 740-748.

Bernard, J. M., \& Goodyear, R. K. (2009). Fundamentals of clinical supervision $\left(4^{\text {th }} \mathrm{ed}\right.$.). Boston, MA: Pearson Education.

Bickmore, D. L., \& Curry, J. R. (2013). The induction of school counselors: Meeting personal and professional needs. Mentoring \& Tutoring: Partnership in Learning, 21(1), 6-27. doi:10.1080/13611267.2013.784057

Corbin, J., \& Strauss, A. (2008). Basics of qualitative research ( $3 \mathrm{rd}$ ed.). Thousand Oaks, CA: Sage.

Council for Accreditation of Counseling and Related Educational Programs. (2009). 2009 Standards. Retrieved from

http://www.cacrep.org/doc/2009\%20Standards\% 20with\%20cover.pdf

Dollarhide, C. T., \& Miller, G. M. (2006). Supervision for preparation and practice of school counselors: Pathways to excellence. Counselor Education and Supervision, 45, 242252.

Erickson, S. (2001). Multiple relationships in rural counseling, Family Journal, 9(3), 302-304.

Hann-Morrison D. (2011) The varied roles of school counselors in rural settings. Georgia School Counselors Association Journal, 18(1), 26-39.

Hendricks, B., Bradley, L. J., Brogan III, W. C., \& Brogan, C. (2009). Shelly: A case study focusing on ethics and counselor wellness. Family

Journal, 17(4), 355-359. doi: $10.1177 / 1066480709348034$

Koch, S. P. (2007). Training rural special educators online to teach social skills. Rural Special Education Quarterly, 26(4), 16-20.

Lambie, G. S., \& Sias, S. M. (2009). An integrative psychological developmental model of supervision for professional school counselorsin-training. Journal of Counseling \& Development, 87(3), 349-356.

Luke, M., \& Bernard, J. M. (2006). The school counseling supervision model: An extension of the Discrimination Model. Counselor Education and Supervision, 45(4), 282-295.

Luke, M., Ellis, M. V., \& Bernard, J. M. (2011). School counselor supervisors' perceptions of the Discrimination Model of supervision. Counselor Education \& Supervision, 50(5), 328-343.

Luke, M., \& Goodrich, K. M. (2012). LGBTQ responsive school counseling supervision. The Clinical Supervisor, 31(1), 81-102.

Luke, M., \& Gordon, C. (2011). A discourse analysis of school counseling supervisory e-mail. Counselor Education \& Supervision, 50(4), 274291.

Luke, M., \& Gordon, C. (2012). Supervisors' use of reinforcement, reframing, and advice to re-author the supervisory narrative through e-mail supervision. Clinical Supervisor, 31(2), 159-177. doi:10.1080/07325223.2013.730020

McAdams III, V. T., \& Wyatt, K. L. (2010). The regulation of technology-assisted distance counseling and supervision in the United States: An analysis of current extent, trends, and implications. Counselor Education \& Supervision, 49(3), 179-192.

McCarthy, C., Van Horn Kerne, V., Calfa, N. A., Lambert, R. G., \& Guzman, M. (2010). An exploration of school counselors' demands and resources: Relationship to stress, biographic, and caseload characteristics. Professional School Counseling, 13(3), 146-158.

Merriam, S. B. (2009). Qualitative research: A guide to design and implementation. San Francisco, CA: Jossey-Bass.

Miller, G. M., \& Dollarhide, C. T. (2006). Supervision in schools: Building pathways to excellence. Counselor Education and Supervision, 45, 296-303.

O'Connell, W. P. (2012). Secondary school administrators' attitudes toward confidentiality in school counseling. National Association of Secondary School Principals, NASSP Bulletin, 96(4), 350-363.

Oser, C. B., Biebel, E. P., Pullen, E., \& Harp, K. L. H. (2013). Causes, consequences, and prevention of burnout among substance abuse treatment counselors: A rural versus urban comparison. Journal of Psychoactive Drugs, 45(1), 17-27. 
Patton, M. Q. (2002). Qualitative research and evaluation methods (3rd ed.). Thousand Oaks, CA: Sage.

Rios, B. D. (1988). "Rural"--A concept beyond definition? Retrieved January 15, 2015, http://www.ericdigests.org/pre-929/concept.htm (ED296820)

Saba, R. G. (1991). The rural school counselor: Relations among rural sociology, counselor role, and counselor training. Counselor Education and Supervision, 30(4), 322-329.

Somody, C., Henderson, P., Cook, K., \& Zambrano, E. (2008). A working system of school counselor supervision. Professional School Counseling, 12(1), 22-33.
Storlie, C. A., \& Smith, C. (2012). The effects of a wellness intervention in supervision. Clinical Supervisor, 31(2), 228-239. doi: $10.1080 / 07325223.2013 .732504$

Sutton, J., M., \& Pearson, R. (2002). The practice of school counseling in rural and small town schools. Professional School Counseling, 5(4), 266-276.

Swank, J. M., \& Tyson, L. (2012). School counseling site supervisor training: A web-based approach. Professional School Counseling, 16(1), 40-47.

U.S. Census Bureau (2010). Urban and rural definitions. Retrieved January 22, 2015, from http://www.census.gov/geo/reference/urbanrural.html

\section{About the authors:}

Tara A. Wilson is an assistant professor in the School of Education and Counseling at Wayne State University.

Susan Schaeffer is an associate professor in counselor education at Chadron State University.

Mary Alice Bruce is a professor in counseling and department head of Professional Studies at the University of Wyoming. 